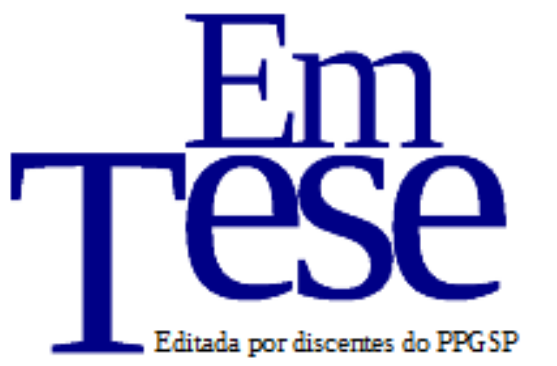

UFSC

PPG SP PROG RAMA DE

PÓS-GRADUAÇÃO EM

Sociologia

Política

v. 14, n. 1, jan./jun., 2017

\title{
A educação como eixo da modernização do Brasil nos anos 1930: a disputa de ideias entre Nacionalistas, Igreja Católica e Escola Nova
}

\author{
Rafael Gonçalves Gumiero ${ }^{1}$ \\ Aline Zambelo ${ }^{2}$
}

\begin{abstract}
Resumo: Nos anos 1930, a ideia do atraso no Brasil esteve condicionada pelo mimetismo cultural, e a saída proposta pelas escolas Nacionalista, Católica e Escola Nova foi o projeto de educação como suporte para formação do ethos nacional por intermédio da cultura. A disputa de ideias entre os projetos de educação destas escolas reverberou do campo simbólico para o institucional, pela normatização do projeto de educação no Ministério da Educação e Saúde, do governo Vargas. O objetivo deste artigo atende a dois movimentos: o primeiro buscar compreender o diagnóstico do atraso e prognóstico do Brasil por intermédio da interpretação de Fernando de Azevedo, pela análise das suas obras A Cultura Brasileira e Novos Caminhos e Novos Fins; o segundo movimento, em que medida o Ministério Capanema adotou diretrizes apontadas nos três projetos em disputa para a formulação do Plano Nacional da Educação.
\end{abstract}

Palavras-chaves: atraso cultural. Modernização. Fernando de Azevedo. Ministério Capanema. escolas de pensamento da educação.

Education as the axis of the modernization of Brazil in the 1930s: the dispute of ideas between Nationalists, Catholic Church and New School

\begin{abstract}
In the 1930s, the idea of backwardness in Brazil was conditioned by cultural mimicry, and the departure proposed by the Nationalist, Catholic and New School was the education project as a support for the formation of the national ethos through culture. The dispute of ideas between the education projects of these schools reverberated from the symbolic to the institutional field, by the normalization of the education project in the Ministry of Education and Heath, the Vargas government. The purpose of this article is two movements: first, to understand the diagnosis backwardness and prognosis of Brazil through the interpretation of Fernando de Azevedo, for the analysis of his works The Brazilian Culture and New Paths and New Ends. The second movement, to what extent did the Capanema Ministry adopt guidelines pointed out in the three projects in dispute for the formulation of the National Education Plan.
\end{abstract}

Keywords: Cultural backwardness; Modernization; Fernando de Azevedo; Ministry Capanema; Schools of thought of education

\footnotetext{
${ }^{1}$ Pós-doutorando no Programa de Pós-Graduação em Sociologia/UFGD. Doutor em Ciência Política pelo Programa de Pós-Graduação em Ciência Política PPGPol/UFSCar. E-mail: gumiero84@gmail.com.

${ }^{2}$ Doutoranda em Ciência Política no Departamento de Ciência Política da Unicamp. Mestre em Ciência Política pelo Programa de Pós-Graduação em Ciência Política PPGPol/UFSCar. E-mail: alinezambello@gmail.com.
} 


\section{Introdução}

No início do século XX, no Brasil, houve uma rotação da interpretação do atraso versus o moderno, que perpassou da interpretação climática e geográfica, da literatura regionalista, para a dos projetos de educação formulados pelas escolas Nacionalista, Católica e Nova, avançaram na sistematização da interpretação para superação do atraso, compreendido sob o signo do mimetismo cultural, pela via da modernização por intermédio da formação do ethos nacional proporcionada pela educação. Apesar das diferenças entre os projetos para a educação nacional das diferentes escolas de pensamento, assemelharam-se em relação ao prognóstico, que demandaria a formulação da política nacional de educação. A institucionalização do Ministério da Educação e Saúde, permitiu que a disputa entre essas escolas de pensamento reverberasse da dimensão simbólica para a institucional, e numa coalizão de ideias o ministro Capanema formulou o Plano Nacional de Educação em 1937, em torno do ideal de educação para o desenvolvimento do Brasil ${ }^{3}$.

O objetivo deste artigo está dividido em dois momentos: 1) apresentar o repertório teórico de Fernando de Azevedo, representante da Escola Nova, balizado pelo seu diagnóstico sobre o atraso cultural do Brasil e o prognóstico para a formação do ethos cultural e a modernização; 2) Balanço das diretrizes adotadas pelo Ministério da Educação e Saúde, na gestão de Capanema, dos três projetos de educação propostos pelas escolas de pensamento, Igreja Católica, Nacionalismo e Escola Nova.

A hipótese deste artigo é a de que a saída do atraso, condicionado pelo mimetismo cultural, seria pela formação do ethos nacional por intermédio da cultura, gerada no processo de expansão da educação da população. No governo Vargas (1930-1945) a formulação do Plano Nacional de Educação, abrigada no Ministério da Educação de Capanema, poderia ser compreendida como plano para formação da cultura no Brasil.

O método adotado para cotejar o objetivo supracitado parte das contribuições de Pocock e Skinner, que apontam a interpretação teórica como meio de alcançar a realidade do fenômeno político e pode ser revisitado após a sua criação, segundo as ações e momentos históricos ocupados pelos atores sociais. Na obra de Pocock (2003) Linguagens do Ideário Político, o método formulado considera a renovação do repertório teórico, determinado pela reflexão sobre um tema imbricado pela revisão dos léxicos e linguagem, que é apropriada pelo teórico e ressignificada em uma nova linguagem que reverbera a parole, ou seja, a interpretação do tema.

Skinner (2000) afirma que o conhecimento do contexto em que o autor escreveu a sua obra é de importância para compreensão do texto, para evitar anacronismos e mitologia das

\footnotetext{
${ }^{3}$ Que não chegou a ser colocado em prática devido ao fechamento do congresso em 1937 (CURY, 2010).
} 
doutrinas ${ }^{4}$. O referido teórico explica que a compreensão dos textos perpassa pela apreensão do que pretende significar a intenção do autor, e descobrir as relações entre este e o contexto linguístico mais amplo como uma forma de compreender a verdadeira intenção do autor, por meio do estudo do universo linguístico no qual ele está imerso.

Neste artigo, observamos uma aproximação da compreensão da modernização pela vertente teórica da educação, que compreenderam o processo de desenvolvimento como difusão da educação. A construção de campo teórico pode ser compreendida pela análise de Karl Mannheim (1982b), de que os intelectuais são capazes de criar sínteses e são portadores de ideologias direcionadas para a transformação e, neste caso, mobilizou as escolas de pensamento (Igreja Católica, Nacionalista e Escola Nova) como portadoras de diferentes ideologias. O teórico supracitado afirma que a produção dos intelectuais possui trajetórias pela qual transitam para legitimar o seu raciocínio: a dimensão interna, a apreensão da realidade histórica e social; a dimensão externa e a transição para a arena intelectual em uma acirrada disputa simbólica de campo com outras interpretações, desagua na contribuição para a transformação da sociedade, ressignifica conceitos e inaugura um novo ciclo de temas e problemas.

A interpretação do pensamento de Fernando Azevedo, em duas de suas obras, A Cultura Brasileira e Novos Caminhos e Novos Fins, busca reposicionar a discussão sobre desenvolvimento pela educação, que assume a conotação de modernização do Brasil. Em um segundo movimento, análise das propostas de projeto de educação das escolas de pensamento Nacionalista, Católica e Nova, e sua influência no Plano Nacional de Educação, do Ministério de Educação e Saúde, de Capanema.

Para Mannheim (1982a) o pensamento político pode ser direcionado para compreensão do processo de formação de identidade, de legitimação e consenso dos indivíduos e nos processos de transformação das sociedades.

$\mathrm{O}$ ponto de partida neste artigo foi diagnosticar o problema do atraso, esse movimento reposicionou a questão do moderno como central para o desenvolvimento do país. A cultura assumiu papel prioritário na interpretação de um conjunto de intelectuais, que problematizaram e superaram a interpretação do determinismo geográfico e climático ao formular um novo repertório, balizado pela ideia de saída de atraso por intermédio da educação.

O período da Primeira República teve uma efervescência de correntes e ideias ligados a grupos políticos. Nagle (1974) aponta seis correntes: a) Socialismo, anarquismo, marxismo; b) Nacionalismo; c) Catolicismo; d) Tenentismo; e) Modernismo e f) Integralismo. Essas correntes,

\footnotetext{
${ }^{4}$ A mitologia das doutrinas pode concorrer para o perigo de conversão de algumas ideias do teórico em sua doutrina sobre temas obrigatórios, o que gera duas distorções, a primeira em que é focado nos pensadores individuais e o outro na história das ideias, em que o ponto central é o desenvolvimento de alguma ideia, descolada do contexto histórico dos pioneiros ou interlocutores.
} 
nesse momento, estão em conformação e em disputa, sendo que algumas apontam que o caminho do Brasil moderno se daria pela via da cultura ${ }^{5}$. Por estar focado principalmente entre 1900 e 1930, Nagle (1974) destaca o Catolicismo e o Nacionalismo como dois ideários fortes ligados à educação. Já Cury (1978) e Scwartzman, Bomeny e Costa (2000) se dedicam a períodos posteriores, agregando a Escola Nova como fonte de disputa do projeto educacional.

Outro resultado identificado foi a conexão dos atores e as suas ligações a três perspectivas de projeto de educação, denominadas ideário. O projeto nacionalista absorveu as ideias da Liga de Defesa Nacional e dos Militares e em certa medida também do movimento Modernista e Integralista ${ }^{6}$ os quais, fundamentalmente, associam a educação com a formação de um povo consciente dos símbolos nacionais e essa percepção promoveria a salvação do inimigo interno aliado à formação de um povo coeso para combate do perigo externo, além de incorporar elementos nacionais (ou a busca sobre o que seria tipicamente brasileiro). O projeto ligado ao catolicismo considerou a educação como a forma de difusão das doutrinas da igreja através da inclusão do ensino religioso na rede pública. Por fim, o projeto da Escola-Nova propôs como diretriz principal a promoção da escola pública de qualidade e universal, pautada no estado laico. O Ministério Capanema acomodou em sua política nacional de educação os interesses, de acordo com as diferentes proposições das escolas de pensamento ${ }^{7}$.

Esse trabalho está dividido em quatro seções, além da introdução. Na primeira seção apresentaremos as diferentes escolas de pensamento da educação, a Escola Nova, a Igreja Católica e os Nacionalistas. Na segunda seção, o pensamento de Fernando de Azevedo e as suas propostas para a educação foram priorizados. Finalmente, na terceira seção, apresentamos o projeto de educação do Ministério da Educação e Saúde Pública de Gustavo Capanema e as influências recebidas das escolas de pensamento da educação.

\section{Ascensão e embate entre os projetos de educação dos Nacionalistas, Igreja Católica e Escola Nova}

No início do século XX, houve a rotação da concepção de atraso no Brasil, a interpretação dos literários regionalistas foi superada pela identificação da necessidade de formação do ethos cultural do Brasil pelas escolas de pensamento da educação. O governo de Getúlio Vargas, em 1930, foi a arena de disputa do campo simbólico entre as correntes

\footnotetext{
5 No momento da conformação do Estado Novo, em 1937, o integralismo apresenta uma proposta para educação, ver mais em Carone (1978).

${ }^{6}$ Como apontado por Nagle (1974).

7 Antes do desenvolvimento do Plano Nacional de Educação em 1937, o Governo Vargas realizou um movimento de diálogo e acomodação dos grupos da Igreja Católica e Escola Nova, como forma de apaziguar e criar laços políticos (CURY, 1978).
} 
ideológicas para elegibilidade do seu projeto de educação, como orientação para o plano nacional do Ministério da Educação. A seguir serão descritas as diretrizes principais que subsidiaram estes projetos, distinguidos em diferentes correntes ideológicas da educação.

A concepção da formação do ethos do Brasil foi discutida inicialmente por um grupo de literários regionalistas e posteriormente foi ressignificada pelos teóricos signatários das escolas de pensamento da educação, o que representou avanço sistemático na interpretação de atraso do Brasil e consequentemente, na proposição de alternativas pela dimensão cultural para a sua superação.

A interpretação proferida pelos literários regionalistas, Euclides da Cunha, Lima Barreto, Machado de Assis, estiveram pautada pelo determinismo geográfico e climático sobre a formação do povo brasileiro. Euclides da Cunha (1969), em 1902, em sua obra Os Sertões partiu do diagnóstico de que miscigenação de raças resultou em "tipos sociais", tal como o homem sertanejo e o litorâneo. Em sua tipologia o ethos do homem do litoral estava conectado ao mimetismo do padrão econômico, cultural do homem da Europa, concebida como locus da modernidade. $\mathrm{O}$ homem do sertão estava em uma constante luta pela sobrevivência no meio em que vive, o que estabelecia um constante embate contra a natureza, o seu meio social é resultado do enfretamento do homem versus meio. Para o referido teórico, o progresso da civilização originaria de elementos nacionais e seria complementado pela sua diversidade.

A superação do discurso do determinismo geográfico partiu da constatação do atraso cultural no diagnóstico do Brasil em relação aos países da Europa e Estados Unidos (países centrais) por um grupo de intelectuais. Essa ideia remeteu ao embate atraso versus moderno, como consequência do processo de colonização no Brasil que estava associado ao tradicional, que assumiu no léxico normativo o sentido de consequência da formação do povo oriunda da colonização da metrópole, ditada pela implantação de instituições do centro e seu desarranjo com a sociedade em formação na colônia, e, pela "vocação agrária" como extensão das atividades econômicas da metrópole. Desse modo, estes teóricos partiram do passado do Brasil para dirimir o diagnóstico de atraso. A ideia de progresso assumiu estreita relação com a cultura, portadora de valores simbólicos imprescindíveis para pensar a modernização.

A passagem da sociedade tradicional ou atrasada para a modernidade no Brasil seria concedida através do campo da cultura, por intermédio da educação como portadora de energias sociais capaz de modificar a cultura e introjetar o ethos da modernidade na população brasileira. Daros (2013) aponta que neste processo houve intensa disputa entre os diferentes projetos de educação. A educação ocupou posição estratégica como sistema de controle e organização social e política. A acirrada disputa de projeto tomou conta da agenda de intelectuais nas décadas de 
1920 a 1940 e as reformas de ensino foram posicionadas como centrais no projeto de modernização da sociedade.

A disputa de ideias sobre a posição que a educação deveria ocupar no processo de modernização do Brasil fomentou a construção de novo repertório de ideias e optamos em apresentá-lo dividido em três projetos de educação: 1) escola de pensamento Nacionalista; 2) escola de pensamento Católico; 3) escola de pensamento Escola Nova. O esforço fica por conta de delinear as principais características de cada um, pavimentadas em um campo nebuloso, de difícil distinção entre uma proposta e outra, dado que o quadro analítico era de déficit na educação e de direitos sociais da população brasileira.

A primeira escola de pensamento abordada é a Nacionalista que compartilhou estreita relação com ideias vinculados à Liga de Defesa Nacional e às ligas nacionalistas estaduais, bem como absorve contribuições do pensamento militarista e dos movimentos modernista e integralista.

A escola Nacionalista absorveu grande influência do contexto, da Primeira Guerra Mundial, e sob signo de temas como a defesa nacional, o seu discurso foi direcionado para a necessidade de um povo consciente do valor da nação e preparado (física e mentalmente) para sua defesa. A educação, com caráter instrutivo, funcionaria no combate ao perigo interno, este, calcado em sentimentos contrários à nação brasileira, em decadência moral de do patriotismo, o que expôs a nação à beira do colapso.

O marco inicial foi a liga da defesa nacional, em 07 de setembro de 1916, o seu expoente foi Olavo Bilac, que fez frente a necessidade de se colocar a instrução como combate ao perigo interno devido ao definhamento do patriotismo e junto com outros movimentos se propôs pensar o Brasil. Esse processo exerceu forte rebatimento na criação das ligas nacionalistas e as estaduais no Brasil, subjacente à formulação da Revista Brazílea -1917 ligado a um grupo autoritário nacionalista e à revista Propaganda Nativista - 1919. Essas revistas foram a principal arena de debate público e defesa de campo desses atores.

Na década de 1920, floresceram as ideias nacionalistas direcionadas para sua adaptação na educação, a partir de "livros didáticos de conteúdo moral e cívico, ou melhor, de acentuada nota patriótica" (NAGLE, 1974, p. 44) para criar o sentimento nacionalista. É nesse momento que temos a nacionalização do ensino primário e as escolas estrangeiras foram fechadas em 1918.

A Liga Nacionalista era formada por uma sede nacional e mantinha diretórios em todos os estados. Em seu regimento, o presidente da república seria a autoridade máxima na sede e os governadores dos estados ficariam responsáveis pelos diretórios e se definiam como “independente de qualquer credo político, religioso ou filosófico, destinada, dentro das leis 
vigentes do País, a congregar os sentimentos patrióticos dos Brasileiros de todas as classes" (NAGLE, 1974, p. 45). Outros objetivos propalados por esta escola de pensamento, eram a difusão do ensino militar nas diversas instituições, promover o ensino da língua pátria nas escolas estrangeiras do país e propagar a educação popular e profissional.

A educação foi posicionada como peça fundamental no discurso da escola Nacionalista, pois era possível privilegiar o serviço militar para fazer frente a ameaça externa e a instrução proporcionada pela educação para instruir a população do perigo interno. Em colaboração à busca pela alfabetização estaria a formação do cidadão político, cuja prioridade seria introduzir no ethos dos cidadãos a nacionalidade mediante a educação popular.

Os militares compuseram em conjunto com os intelectuais este grupo e reafirmaram que a educação deveria ser baseada nos princípios da disciplina, obediência, organização, respeito à ordem e às instituições como forma de acabar com o pacifismo ingênuo da sociedade brasileira. Além disso, a educação estaria vinculada à questões da segurança nacional. Para Azevedo Amaral (1940, n. 4, p. 29) “O que se deve pretender é a formação intelectual e moral das novas gerações fora da atmosfera depressivas das utopias pacifistas. A segurança de uma nação somente será consolidada quando o povo estiver inflamado pelo espírito militar" (apud SCHWARTZMAN, BOMENY, COSTA, 2000, p. 69).

Por fim, o ideário nacionalista de educação foi composto principalmente das seguintes características: i) a instrução de massas para formação de povo político nacionalizado; ii) pautado na obediência e na difusão de símbolos nacionais.

Em 1891, a separação entre a Igreja e o Estado também fez com que a educação religiosa saísse do currículo escolar. Nesta ruptura, não houve um pessimismo em relação à situação anterior (no qual a igreja era "dominada" pelo Estado).

O ajustamento à nova ordem social não foi traumático para os católicos brasileiros, como acontecera em outros países. O novo regime foi implantado e a acirrada batalha entre católicos e liberais e entre católicos e positivistas ou maçons foi cessada de maneira progressiva" (NAGLE, 1974, p. 57).

Para Cury havia um reconhecimento por parte de intelectuais vinculados à Igreja Católica da não influência na Constituição de 1891, bem como na Reforma de 1926, "porque não possuíam homens habilitados para tal. E a causa foi a falta de instrução natural, moral e religiosa da sociedade" (CURY, 1978, p. 61-62).

Havia, dentre a intelectualidade católica, intenção de participar da vida política a partir da criação de um partido para consolidação da "Democracia Cristã" como pensado por Jackson de Figueiredo e vetado por Dom Leme (Martins, 1996). Em 1916, a Carta pastoral de D. Sebastião Leme defendeu como prioridade a intensificação do católico a serviço das práticas religiosas (de 
modo a não se limitar na igreja, mas nos meios intelectuais, nas escolas, imprensa, indústria, comércio etc). Nos anos 1920, a fundação da revista "A ordem", foi intrínseca a este movimento e foi responsável pela difusão do ideário católico com propósito de implementar as reformas políticas e culturais. Jackson de Figueiredo foi o fundador da revista e Alceu Amoroso Lima, vinculado aos ideais católicos, assumiu a sua direção (DAROS, 2013).

Para Nagle (1974) a revista "A ordem” combinou em seu conteúdo aspectos mais políticos e suas publicações estiveram mais próximas à cultura. No projeto católico prevaleceu a ideia:

Desobedecer a uma autoridade é desobedecer a Deus e, portanto, o espírito revolucionário é o espírito anticristão. A ordem, que não tem ilusões sobre a democracia e, particularmente, sobre a nossa República, está no entanto, e de modo absoluto ao lado da legítima autoridade do país" (NAGLE, 1974, p. 63).

A Confederação Católica, fundada em 1922, funcionou como movimento de arregimentação dos leigos católicos, que compreendeu a união de indivíduos para a ação dos ideais ditados pela igreja. Entre 1924 e 1926, foi aberta a revisão da Constituição e nessa oportunidade os católicos apresentaram algumas reivindicações, como o ensino religioso nas escolas e também a declaração da religião católica como oficial do país, o que proibiu outra igreja de formar relações de dependência ou aliança com o governo. Esse período florescente na década de 1920 tinha intenções claras de acabar com uma tendência laicista trazida com a República.

Segundo Daros (2013) a igreja católica nos anos 1929 a 1932 exerceu papel determinante na proposição de um projeto de educação ao governo, ao ocupar a direção da Associação Brasileira de Educação $\left(\mathrm{ABE}^{8}\right)$. O controle técnico e doutrinário das escolas foi alvo da disputa de projetos entre os católicos e os pioneiros (Escola Nova). Os católicos compreenderam a educação como um espaço estratégico de atuação e lançou uma proposta de sociologia cristã, cujo papel fundamental é reespiritualizar a cultura, esta ação alcançou um papel político no Estado e na sociedade.

O pensamento católico no Brasil pode ser dividido em diferentes vertentes. Dom Sebastião Leme conduziu a vertente conservadora da neocristandade da cúpula da hierarquia eclesiástica brasileira até a década de 1940. Posteriormente, após a sua morte, houve uma guinada do pensamento da esquerda católica nas instituições da hierarquia católica, tutelada por D. Helder Câmara e consolidada pela inauguração da Conferência Nacional dos Bispos do Brasil (CNBB). Nos anos 1940, houve uma aproximação desta vertente do pensamento católico com o

\footnotetext{
${ }^{8}$ A Associação Brasileira de Educação, fundada em 1924, sediou o movimento de renovação educacional no Brasil. Reuniram-se, os grupos de educadores, mobilizados pela "causa cívico-educacional”, concomitantemente às Conferências realizadas, o que pode ser associada a arena de disputas simbólicas e políticas sobre a questão da educação, dentre elas, foi palco, em 1932, do Manifesto dos Pioneiros da Educação Nova (DAROS, 2013).
} 
grupo Economia e Humanismo ${ }^{9}$, com uma perspectiva do desenvolvimentismo humanista orientado pelo planejamento e a intervenção do Estado na formulação de ações para superar o subdesenvolvimento dos países (GODOY, 2015).

O Ministério da Educação e Saúde sob a batuta de Francisco Campos revogou a disposição da Constituição de 1891 e autorizou o ensino religioso em 1931. No ano seguinte, o interventor de São Paulo, Fernando de Azevedo, retirou a possibilidade de ensino religioso. "Alceu Amoroso Lima levanta-se contra o manifesto dos Pioneiros da Educação Nova, que sugere a concentração do ensino nas mãos do Estado, contribuindo assim, segundo ele, para a implantação do regime comunista" (SCHWARTZMAN, BOMENY, COSTA, 2000, p. 58). A educação orientada pela igreja católica teve como diretriz fundamental o ensino para todos, pautado pela obediência através da educação religiosa.

A partir de 1932, o Manifesto dos Pioneiros consolidou a Escola Nova como via ideológica alternativa da educação. Alguns dos fatos que orientaram a construção desse ideário foram a reforma de Leôncio de Carvalho (1879), parecer de Rui Barbosa (1881-1894) sobre a reforma da escola primária, criação de escolas protestantes e o espalhamento de laboratórios psicopedagógicos. No período da República, foram representações bibliográficas dessa via: $A$ educação nova (1912) de Ciridião Buarque e Princípios de Pedagogia (1914) de Sampaio Dória. Nessa fase, o ideário escolanovista esteve relacionado com a inversão da relação aluno/professor.

A Escola Nova apresentou a ideia de educação para todos de forma gratuita e laica, a partir da necessidade do indivíduo (em contraposição à educação de massa). Foram determinantes nesse movimento o grupo formado por Anísio Teixeira, Fernando de Azevedo, Manuel Lourenço Filho, Francisco Campos (com a reforma de 1920).

De modo geral, esse grupo atribuía o desenvolvimento de uma sociedade rumo à civilização enveredado pelo tratamento dado às ideias morais no sentido da empatia e do trabalho coletivo, onde a escola assumiu local privilegiado para reprodução desse ethos de vivência e se os novos ideais educacionais propostos fossem assumidos pela 'nova política' do Brasil, funcionariam como o músculo central da estrutura política e social da nação (CURY, 1978, p. 81).

O próximo tópico apresenta a tese da educação de Fernando de Azevedo, considerado um dos principais signatários do pensamento da Escola Nova e exerceu influência no cenário político/educacional.

\footnotetext{
${ }^{9}$ Segundo Godoy (2015) as teses marxistas e anarquistas foram recepcionadas por este grupo, porém não houve adoção dos temas de lutas de classes e socialismo, o que derivou como uma terceira via ao pensamento dos liberais e comunistas, denominado desenvolvimentismo humanista. A interpretação desta terceira via considerou como estratégia se debruçar sob a questão do subdesenvolvimento e como superá-lo.
} 


\section{A contribuição de Fernando de Azevedo para a formulação do projeto da educação da} Escola Nova

Nascimento (2012) apresenta a trajetória intelectual de Azevedo em diferentes fases do seu pensamento: 1) as obras Da Educação Física, 1915, Novos Caminhos e Novos Fins, 1932, A cultura brasileira, 1943, trabalharam direcionadas para a compreensão do papel das ciências (Sociologia) no desenvolvimento da Sociologia brasileira; 2) as obras A cidade e o campo na civilização industrial, de 1962, Princípios de Sociologia, de 1935, Sociologia educacional, de 1940, A cultura brasileira, de 1943, As ciências no Brasil, de 1955, apresentaram a institucionalização da Sociologia do país e definições conceituais que compuseram a sua versão sobre o instrumental teórico metodológico dessa ciência; 3) as obras A cidade e o campo na civilização industrial, 1962, Canaviais e engenhos na vida política do Brasil, 1948, e Um trem corre para o Oeste, 1950, reuniram como tema a transição da tradição para a modernidade balizada pela ideia de complementaridade entre desenvolvimento e mudança social.

O pensamento de Azevedo compreende a cultura como o eixo da modernização para sociedade brasileira. Nesse aspecto a educação assume papel principal na circulação e introdução de valores estabelecidos pela cultura. As instituições de ensino, escolas e universidades, herdaram essa ideologia como meio para o desenvolvimento da nação.

Dentro da longa trajetória da produção bibliográfica de Fernando de Azevedo optamos por estabelecer um recorte menor, com ênfase na potencialização que a cultura adquiriu, compreendida como portadora de racionalidade, capaz de provocar mudanças no ethos da sociedade brasileira. Nesse recorte utilizamos as seguintes obras de Fernando de Azevedo: Novos Caminhos e Novos Fins, de 1927; A Cultura Brasileira, de 1943.

A justificativa pela escolha dessas obras foi a inserção em seu discurso de um novo parâmetro para pensar o moderno versus o atraso, apresentou como alternativa para superação do atraso a inserção da educação na sociedade, adotando parâmetros da função da intelligentsia ${ }^{10}$, extravasado pela ação a tarefa de difusão da cultura na sociedade.

Essa função é, por conseguinte, uma função de produção, de circulação e de organização no domínio espiritual: criadora de valores e de bens espirituais, com que instaura um domínio que é uma pátria e um asilo para todos, a inteligência não só os distribui e se esforça por torná-los acessíveis a um maior número possível, como empreende a organização da sociedade, segundo pontos de vista espirituais, "atingindo a sua mais alta expressão quando empreende organizar a vida moral". A cultura, pois nesse sentido restrito, e em tôdas as suas manifestações, filosóficas e científicas, artísticas e literárias, sendo um esfôrço de criação, de crítica e de aperfeiçoamento, como de realização de ideais e valores espirituais, constitui a função mais nobre e mais

\footnotetext{
${ }^{10} \mathrm{O}$ termo utilizado de intelligentsia foi adotado das teses de Karl Mannheim, combinam a formação da geração de intérpretes que articulam campo e agenda do debate, e a ação política dos intelectuais, que reverberam suas teses como ideologia ou utopia.
} 
fecunda da sociedade, como a expressão mais alta e mais pura da civilização (AZEVEDO, 1963, p. 38).

Em 1927, Azevedo foi convidado para empreender a reforma do ensino no Rio de Janeiro, Distrito Federal do Brasil. Nesta oportunidade, ele publicou o livro Novos Caminhos e Novos Fins, que resultou de uma coletânea de conferências realizadas por ele como diretor da Instrução Pública do Distrito Federal-RJ, enveredou pela defesa aos intelectuais católicos com diretrizes diferentes para a educação no Brasil.

O propósito desta obra para Azevedo foi de difusão no meio cultural, político e educacional brasileiro das ideias da Escola Nova. Esta obra pode ser compreendida com uma defesa de campo simbólico na disputa política pela inserção do projeto de educação em instituições de ensino do Estado. As ideias produzidas por intelectuais circularam nos acalorados debates entre os intelectuais e transitaram às instituições de ensino, exerceu a função norteadora de políticas de educação.

No livro, a Cultura brasileira, de 1943, Azevedo tratou das questões ligadas a tradições culturais e reafirmou que a educação era a instituição responsável por transmitir valores, visões, enfim patrimônio material de uma geração a outra, assegurando a coesão social. E, em um momento de crise, a educação se transformou em um instrumento privilegiado para desencadear novas tradições e superar as antigas. Assim, a vitória das novas tradições representou a garantia do restabelecimento do equilíbrio social e da evolução civilizacional do país. Essa obra foi produto do censo de 1940, encomendado a Azevedo, e parte do projeto Coleção Científica Brasiliana $^{11}$.

Azevedo (1963) registra um importante movimento pela renovação das diretrizes da educação no Brasil, no "Manifesto dos Pioneiros da Educação Nova", apresentado ao povo e ao governo. Foi publicado em 1932, no Rio de Janeiro e São Paulo, as diretrizes de uma política escolar, inspirada em novos ideais pedagógicos e sociais, com objetivo de alcançar uma civilização urbana e industrial, de modo que rompesse contra as tradições individualistas da política do país. Os vetores desse programa foram a solidariedade nacional e a adaptação das diretrizes escolares às mudanças econômicas e sociais em processo no país.

A defesa do princípio de laicidade, a nacionalização do ensino, a organização da educação popular, urbana e rural, a reorganização da estrutura do ensino secundário e do ensino técnico e profissional, a criação das universidades e de institutos de alta

\footnotetext{
${ }^{11}$ Dutra (2006) compreende que a Coleção Brasiliana teve papel fundamental na formação da intelligentsia no Brasil e na legitimação da área da Sociologia e na sua inserção no processo de expansão da cultura no Brasil, nos anos 1930. A autora dirime que a coleção Brasiliana provocou três implicações: 1) estabeleceu uma noção de interpretação da identidade nacional; 2) indicou caminhos para formular diagnóstico e alternativas para o Brasil por intermédio de políticas públicas; 3) a coleção Brasiliana colaborou para estruturar a mentalidade dos leitores, os orientando em suas visões sobre o Brasil.
} 
cultura, para o desenvolvimento dos estudos desinteressados e da pesquisa e científica, constituíam alguns dos pontos capitais dêsse programa de política educacional, que visava fortificar a obra do ensino leigo, tornar efetiva a obrigatoriedade escolar, criar ou estabelecer para as crianças o direito à educação integral, segundo suas aptidões, facilitando-lhes o acesso, sem privilégios, ao ensino secundário e superior, e alargar, pela reorganização e pelo enriquecimento do sistema escolar, a sua esfera e os seus meios de ação (AZEVEDO, 1963, p. 667).

A formulação e divulgação das diretrizes de uma política da educação estabeleceu novo marco para reposicionar o papel dela no processo de desenvolvimento do Brasil. Ademais, permitiu inaugurar uma nova fase de ação amparada pelo domínio das ideias. Apesar de diferentes posicionamentos das correntes ideológicas da educação havia consenso pela renovação pela implementação de um plano escolar para o Brasil (AZEVEDO, 1963).

A campanha para a renovação pedagógica foi intensamente debatida em conferências e esboços de planos empreendidos pelos embates entre os representantes da Escola Nova e os católicos. Em 1932, na V Conferência Nacional de Educação, sediada em Niterói, foi aprovado o desenho do plano nacional de educação. No ano seguinte, no simpósio organizado pelo Departamento do Rio de Janeiro da Associação Brasileira de Educação, o conselho diretor concluiu o texto final da proposta de um plano nacional de educação, que conciliou demandas da Escola Nova e da Católica (AZEVEDO, 1963).

A Carta de 1934 instituiu medidas que assegurasse a formulação de um plano nacional de educação. Entre as suas diretrizes destacamos as demandas levadas pela escola de pensamento da Escola Nova, que reconheceu a educação como um direito de todos, instituiu a liberdade do ensino em todos os graus, a gratuidade e obrigatoriedade do ensino primária ao ulterior. A educação tomou bases democráticas sendo balizada por essas diretrizes e difusão do ensino, que se manteve concentrado a uma pequena fração da população adolescente, oriunda da burguesia (AZEVEDO, 1963).

Azevedo na posição de diretor da Instrução Pública do Distrito Federal tomou como ponto de partida a realização do recenseamento escolar para formular o diagnóstico da situação educacional do Distrito Federal. Em paralelo a sua atuação institucional, a sua obra Novos Caminhos e novos fins propôs medidas para a reorganização da diretoria do ensino normal em âmbito nacional: a) alteração do ensino normal; b) a construção de novos prédios, c) organização do ensino primário, que se tornou obrigatório e gratuito; d) remodelação das escolas, seguindo a vocação econômica de cada região; e) obrigatoriedade da ginástica pedagógica em todas as escolas e a construção de praças de jogos; f) a formação de professores e o desenvolvimento de uma parceria com esses atores (AZEVEDO, 1931).

A gestação de um projeto de industrialização incentivada pelo Estado promoveu na civilização constantes mudanças e a reforma da educação deveria acompanhá-las, por meio de alternativas que combinadas à industrialização propusessem o país sair do atraso. A educação foi 
compreendida como prognóstico ao atraso do Brasil e dinamizou estímulos para transformação social.

\begin{abstract}
Para este fim, a reforma articulou a escola com o meio social, modificou a sua estructura, remodelando-a num regimen de trabalho e de vida em commum, sob a feição de uma comunidade em miniatura, em que seriam utilisadas as diversas formas de actividade social, que desenvolvem o sentimento de responsabilidade, de sociabilidade e de cooperação. A reorganização estructural da escola, a instituição do exercício normal do trabalho em commum e a utilização, na escola, das formas de actividade social (caixas econômicas, bancos, cooperativas escolares etc) são os meios para a escola socializada adaptar-se cada vez mais ao fim social que a reforma attribuiu aos seus esforços (AZEVEDO, 1931, p. 22).
\end{abstract}

Para Azevedo (1931) a educação nova assumiu como diretrizes a ideia de igualdade, de solidariedade social e de cooperação que constituíram os fundamentos do regime democrático, subjacente às ideias de pesquisa racional, trabalho criador e progresso científico. A educação nova surge como um plano de ação balizada pela ideia de cooperação social, ideia catalisadora de todas as forças e instituições sociais, como a escola, a família, os pais e professores. A sua proposta é de união das diferentes classes em torno dessa diretriz, e o incentivo a interação do sistema pedagógico com o seu meio social, foi introduzida na sociedade.

O ideal da reforma proposto pela Escola Nova foi a ação, isto é, o espírito de iniciativa, a consciência da necessidade do esforço para afirmar-se, o gosto, o hábito, a técnica do trabalho e o respeito a personalidade de outro, afirmando o sentimento de trabalho em cooperação. Sendo assim, ela está dividida em três importantes alicerces: 1) escola única; 2) escola do trabalho; 3) escola comunidade (AZEVEDO, 1931).

O Estado deve providenciar para a população um sistema de educação conforme as condições sociais e econômicas do meio. O primeiro princípio defendido pela Escola Nova é o ensino público obrigatório e gratuito como direito de toda sociedade, para a formação e desenvolvimento do espírito de uma democracia social. O segundo princípio é considerar a educação como um meio de conciliação entre a escola e o trabalho. A ideia de organização deve ser estar presente na formação do estudante, de modo a permiti-lo associar o trabalho manual e a prática de aprendizado, colaborando para despertar o hábito e a técnica de trabalho nos estudantes. A escola é considerada um laboratório que orienta e estimula as atividades educativas. O terceiro princípio fundamental da escola nova é o de comunidade. Essa doutrina propõe conciliar a vida e o trabalho dos indivíduos, ensinando a viver em sociedade e a trabalhar em cooperação. O aluno não deve exercer a sua atividade isoladamente, quando possível em grupos, de modo a se aproximar da ideia de cooperação. Não se trata de preparar o indivíduo para o processo de aprendizagem, mas à sociedade, incutindo a ideia social, desenvolvendo a habilidade de colaboração para aperfeiçoar o rendimento do trabalho, instituir a organização do trabalho em uma sociedade (AZEVEDO, 1931). 
A formação das classes dirigentes e a educação das massas populares são duas faces de um problema, cuja sua resolução depende a estabilidade da estrutura social e o próprio equilíbrio político das instituições. Azevedo (1931) ressalta que a ausência da educação popular resulta em uma sociedade aristocrática, restringe a formação do curso superior em centro universitário à elite. Por outro lado, a educação da população com ausência da formação de elites capazes de orientá-las e dirigi-las, mobilizaria forças para a pior das demagogias. Portanto, a educação progressiva deve ser acessível às camadas populares, expandindo a ação às elites intelectuais pela difusão da cultura, de modo que estabeleça a renovação de dirigentes em modelos de governos democráticos.

Azevedo (1931) compreende que o novo papel da escola na sociedade está vinculado à conscientização do papel dos educadores como operadores, com função social, dessa "reforma" na sociedade. O confronto da escola com outras instituições sociais criou uma nova política de educação, reorganizou a escola, um regime de vida e de trabalho em sintonia. Essa nova concepção de organização introduzida na sociedade pela educação buscava dar eficiência maior a esses setores da sociedade, levando-os a cooperar com outras instituições sociais. O professor nesse processo foi considerado como o "agente social", com alto espírito de cooperação. A nova concepção do lugar da escola na vida e compreensão mais nítida da sua função social despertou a necessidade de transformar a escola num centro de influências educativas, capazes de repercutir sua ação em outras instituições políticas, sociais e religiosas.

\section{O Ministério Capanema enquadramento dos projetos concorrentes de educação}

A intelligentsia assumiu posição central na proposição de projetos de educação e reverberaram em políticas educacionais no Ministério da Educação e Saúde Pública. Segundo Daros e Pereira (2015) a escola de pensamento dos educadores reformistas foi representada por Francisco Campos neste ministério, de 1930 a 1934, e responsável pela formulação da Constituição do Estado Novo. Seu sucessor na pasta, foi Gustavo Capanema, de 1934 a 1945, articulou uma coalizão de projetos educacionais em disputas na dimensão institucional, com o propósito de fundamentar uma "cultura oficial".

A intelligentsia católica foi representada em todas as esferas políticas e culturais do Estado. Alceu Amoroso Lima, um dos principais protagonistas intelectuais da Igreja Católica, propôs ao ministro Capanema o ensino religioso católico como parte da educação básica, aliado a implantação de Universidades Católicas, e acentuou a necessidade de diretrizes nacionais da educação, formalizadas pelo plano nacional de educação. A renovação da Igreja Católica teve como uma das suas bases a atuação de Amoroso Lima, na formação do o Instituto Católico de 
Estudos Superiores, em 1932, da Universidade Santa Úrsula, em 1937, e da fundação da Universidade Católica do Rio de Janeiro, em 1941. Além de ocupar a posição de reitor da Universidade do Rio de Janeiro (DAROS, PEREIRA, 2015).

Segundo Godoy (2015), nas décadas seguintes, dos anos 1940 aos 1960, Lebret e Dom Helder ocuparam espaço nos governos Vargas, Kubistchek e João Goulart e inspirados pela via do desenvolvimentismo católico propuseram diagnósticos e prognósticos na agenda desenvolvimentista do Brasil. A questão do desenvolvimento regional ocupou prioridade na agenda da igreja católica na produção de diagnóstico do Nordeste e Pernambuco. A CNBB protagonizou a organização do I Congresso dos Bispos do Nordeste, em 1954, o que antecedeu a política de desenvolvimento regional da Operação Nordeste. Dom Helder foi convidado e participou da formação do Grupo de Trabalho de Desenvolvimento para o Nordeste (GTDN) e da Superintendência de Desenvolvimento para o Nordeste (SUDENE).

Azevedo ocupou importantes cargos de gestão pública, dentre elas o de Diretor da Instrução Pública no Distrito Federal e promoveu a reforma da educação no Rio de Janeiro, nos anos 1927 a 1930, formatado pela dimensão técnica e que cooperou para o desdobramento das linhas gerais do sistema nacional de ensino no Brasil. Estes intelectuais ao participarem de importantes reformas educacionais se credenciaram como políticos da educação, capazes de fortalecer como representantes da intelligentsia a organização das instituições educacionais, culturais e científicas no país (NASCIMENTO, 2012).

Os católicos não se limitaram a empreenderem formas de resistência ao avanço dos pioneiros, mas a difusão da escola da Igreja Católica foi intermediada por Alceu Amoroso Lima e outros militantes desta causa educacional a partir da sua concepção de educação. Daros e Pereira (2015) apontam como formas de propagação do ideário católico a formação de clubes de formação de docentes e alunos influenciados pela recepção teórica das publicações das obras de seus representantes, Alceu Amoroso Lina e Theobaldo Miranda Santos, que interpretaram a sociologia constituía-se como ciência auxiliar da pedagogia, sendo a filosofia e a ética cristã as definidoras das finalidades da educação (DAROS e PEREIRA, 2015, p. 260).

Como já apontado, a década de 1930 é um ponto de inflexão na vida política brasileira. O que há de comum nos três ideários apresentados é uma perspectiva de crise (seja pela falência do liberalismo, seja pela ameaça comunista) e que precisa ser resolvido. O destaque dado aos três grupos coloca a disputa desses projetos em pauta, sendo que, a base deles está calcada no desenvolvimento de uma política de educação nacional. A diferença se dá fundamentalmente pelas diferentes ideologias associadas às suas trajetórias políticas. 
Além da disputa entre os projetos de educação, Cury ressalta que o embate ideológico entre a Escola Nova e a Igreja Católica circulou em outros circuitos institucionais, como no caso, da Constituição de 1934, sendo que, do ponto de vista das ideias,

Os católicos alinhar-se-ão dentro de uma proposta autoritária e sacral de educação que visa a manutenção da estrutura oligárquica (...). Os Pioneiros alinhar-se-ão na corrente das mudanças. Uns, com propostas mais abertas e democráticas, outros subalternando a democracia ao papel dirigente das 'lite'. Mas todos na linha de adaptação da política educacional ao avanço do capitalismo no Brasil (CURY, 1978, p. 172-173).

Dessa forma, para o autor, a opção de acomodação de interesses na Constituição de 1934 atendeu aos anseios (ainda que parciais) de dois grupos que serviam de base de apoio do Governo Vargas e que, apesar de diferenças ideológicas, apresentavam princípios que atendam aos anseios do capitalismo Brasileiro.

Mas, apesar dessa acomodação, grupos políticos continuaram atuando em busca da implementação de suas ideias nos períodos seguintes. Em 1936, Capanema assumiu a pasta em meio a uma disputa entre projetos educacionais e distribuiu um questionário ${ }^{12}$ entre professores, estudantes, jornalistas, políticos, cientistas, formado por 207 quesitos, com o propósito de instituir inquérito para estruturar as bases para a construção de um Plano nacional de educação.

Após a apuração do questionário, a Liga de Defesa Nacional e a Igreja Católica se organizaram para produzir um documento ao ministério. Ambos produziram o relatório pelo ponto de vista das instituições, permitindo nos apontar uma possível retomada sobre a questão da disputa em pauta. O questionário, portanto, representou o debate da época e o posicionamento dos atores em relação aos recursos disponíveis.

Por sua vez, os representantes da corrente da "Escola Nova" apoiaram a centralização da educação no estado em nome da democratização do ensino, cultura e igualdade social. A centralização permitiria que os cargos que eles ocupavam fizessem a ponte com a realização dos seus projetos.

Por outro lado, a Igreja Católica defendia a total liberdade de ensino (inclusive o religioso) e a autonomia das escolas, dado que a possibilidade da subordinação da educação pelo estado poderia impedir a educação religiosa, como aconteceu no estado de São Paulo, em 1932, pela interventoria de Fernando de Azevedo.

Enquanto isso, os militares utilizaram a educação como slogan para servir à segurança, ordem e continuação da nação e passam a se posicionar como especialistas em educação nacionalista. Eles defendiam a educação moral e cívica.

O resultado da apuração do questionário foi um plano com 504 artigos e metas para 10 anos de existência. O plano contemplou diversos temas como diretrizes, finalidades,

\footnotetext{
${ }^{12}$ Trata-se do Inquérito sobre a instrução pública em São Paulo, encomendado pelo jornal "O Estado de São Paulo".
} 
modalidades, controle e financiamento. Em 17 de maio de 1937 foi assinada a versão final do anteprojeto. No dia subsequente, o anteprojeto foi enviado ao presidente que encaminhou à Câmara dos Deputados para a apreciação e aprovação para efeito de lei. Em 23 de agosto de 1937 foi implantada a Comissão do Plano Nacional de Educação que discutiu amplamente todos os pontos até o instante em que, pelo fechamento do congresso em novembro de 1937 , impedindo o plano de ir para prática. (CURY, 2010).

Alguns pontos do plano foram de importante destaque como a definição da educação: “formar o homem completo, útil à vida social, pelo preparo e aperfeiçoamento de suas faculdades morais e intelectuais e atividades físicas, sendo tarefa precípua da família e dos poderes públicos” (SCHWARTZMAN, BOMENY, COSTA, 1984: 182).

A educação religiosa ficou garantida em todos os níveis de ensino, de acordo com a religião do aluno e no ensino público deveria ser regulado pelas autoridades locais, isso garantiu o atendimento aos anseios da Igreja. Igualmente foi institucionalizada a educação moral e cívica, regulando-a minuciosamente, de modo que as propostas dos militares também ficaram contempladas.

Por fim, o ministro considerou importante a educação superior, no referido plano, e ocupou 40 páginas e 195 artigos somente dedicados a ela. Além disso, em comunicação com o presidente Getúlio Vargas, em 14/11/1935, quando foi entregue o projeto de reorganização do Ministério da Educação, indicou que o ministro priorizasse o ensino superior federal público.

O ministério Capanema priorizou o projeto universitário e as elites dariam conta do problema civilizador brasileiro. O termo elite poderia ser compreendido como corpo técnico e não se restringiu aos escritores e artistas. Só com verdadeiras elites se resolveria, não somente o problema do ensino primário, mas o da mobilização de elementos capazes de movimentar, desenvolver, dirigir e aperfeiçoar todo o mecanismo de nossa civilização (SCHWARTZMAN, BOMENY, COSTA, 1984).

O núcleo desse projeto foi a Universidade do Brasil, uma continuação da Universidade do Rio de Janeiro. A universidade deveria ser centrada na faculdade de Filosofia e Letras. O projeto da Universidade do Brasil se desdobrou em quatro atividades principais: 1) o desenvolvimento da própria concepção da universidade; 2) seu planejamento físico, que deveria se materializar na Cidade Universitária; 3) a criação de uma faculdade de filosofia, ciência e letras; 4) e, a construção do campus universitário. A Universidade do Brasil deveria ser um modelo para todas as universidades nacionais.

O plano foi denominado ambicioso pela mídia e chamado de megalomania, pois a educação primária ficaria sucateada em favor do gasto enorme na educação superior. 
Os anos e esforços dispensados no planejamento da cidade universitária foram em vão, já que o atual campus da Universidade do Rio de Janeiro foi construído em outro local e com outros projetos. A faculdade nacional de filosofia, apesar de ter-se consolidado em alguns de seus cursos e programas, não chegou a capturar a mística e as esperanças que cercara a Universidade do Distrito Federal, nem conseguiu se equiparar ao nível de qualidade de sua congênere e antecessora paulista, criada em 34. A tentativa de dar à nova faculdade um conteúdo ético e filosófico de cunho católico não chegou a ganhar corpo, tendo a própria igreja partido para a criação de sua universidade independente. A faculdade de economia jamais chegou a ser constituir no centro de formação de líderes nacionais a que se destinava incialmente (SCHWARTZMAN, BOMENY e COSTA, 1984: 226).

O ministério obteve sucesso em implantar uma série de reformas administrativas e de procedimentos. O maior desafio do seu plano de ação foi priorizar o sistema universitário por um regimento normativo, padronização de currículos e padrões que fossem válidos em todo o país. No entanto, fracassou na execução literal do projeto universitário.

\section{Considerações finais}

A instauração da República, em 1889, abriu caminho para o Brasil ingressar na modernidade através da complexa e tensa tarefa de interpretá-lo. Os intelectuais assumiram essa tarefa de interrogar o presente subjacente ao olhar o horizonte, em busca de alternativas para a superação dos obstáculos para o desenvolvimento da nação. O ponto de partida foi diagnosticar o problema do atraso, esse movimento reposicionou a questão do moderno como central para o progresso do país. A cultura assumiu papel prioritário na interpretação de um conjunto de intelectuais, que problematizaram e superaram a interpretação do determinismo geográfico e climático ao formular um novo repertório, balizado pela ideia de saída do atraso por intermédio da educação.

A concepção de diagnóstico e prognóstico foi consolidada como método para a produção de interpretações do Brasil a partir dos anos 1920. No campo cultural, a educação surgiu como prioridade e ocupou ao lado do projeto de industrialização papel protagonista na agenda do Estado. Nesse momento o ideário se materializou nas reformas educacionais resultado de um feroz debate entre as correntes ideológicas concorrentes, Igreja Católica, Nacionalistas e Escola Nova. Essas correntes produziram projetos de educação e houve intensa disputa pela institucionalização do projeto político.

Neste trabalho identificamos os atores e as suas ligações a três perspectivas de projeto de educação, denominadas ideário. O projeto nacionalista absorveu as ideias da Liga de Defesa Nacional e dos Militares, os quais, fundamentalmente, associam a educação com a formação de um povo consciente dos símbolos nacionais e essa percepção promoveria a salvação do inimigo interno aliada à formação de um povo coeso para combate do perigo externo. O projeto ligado ao catolicismo considerou a educação como a forma de difusão das doutrinas da igreja através da 
inclusão do ensino religioso na rede pública. Por fim, o projeto da Escola-Nova propôs como diretriz principal a promoção da educação pública de qualidade e universal, pautada no estado laico.

Os projetos, ideários e os atores orientaram pelos programas políticos propostos, pelas escolas de pensamento da educação, o que nos permite afirmar que há pontos de proximidade e de distanciamento entre eles. Por exemplo, a ideia da difusão do ensino para a sociedade foi recorrente nas três escolas, evidentemente com posicionamentos diferentes, oscilou do posicionamento marginal no ideário católico para um posicionamento central no nacionalista, apreendido como responsável para a formação de massas. A escola nova idealizou a educação como um projeto emancipador e essencial para a formação do indivíduo e da sociedade brasileira.

Dada a importância do projeto da escola nova, buscamos compreender os seus ideais pelo pensamento de Fernando de Azevedo. É difícil separar o protagonismo que Azevedo exerceu como representante dos ideais da "Escola Nova" em instituições de ensino, do teórico que produziu uma longa bibliografia. É possível afirmar que a militância de Azevedo em defesa da "Escola Nova" foi presente em todas as instâncias que ocupou, podendo ser interpretada as suas obras Novos caminhos e novos fins e A cultura brasileira como uma resposta aos projetos concorrentes de educação, o que permitiu a circulação de ideias entre a intelligenstia e a recepção delas nas instituições, influenciando os policy makers.

Para Azevedo (1963) apreender as diversidades e as suas conexões em uma sociedade, sobretudo considerando a alma do povo, a terra, os homens e as instituições são elementos basilares na formação do Brasil. A busca pela interpretação da identidade do povo brasileiro esteve no nível das ideias morais. Os princípios norteadores para o desenvolvimento do Brasil associaram a noção de cooperação que deve ser introduzida na sociedade, o que contribuiria para a conscientização da necessidade esforço, o sentimento de responsabilidade e o espírito de cooperação, rompendo com o individualismo e subjetivismo em um ambiente espiritual de trabalho e de alegria.

A luta pelo Plano Nacional da Educação recebeu importantes subsídios da Escola Nova, em específico da produção intelectual de Azevedo, e foi resultado do amplo movimento nacional formado a partir dos anos 1920 e que em 1932 produziu o "Manifesto dos Pioneiros da Educação". Esse documento defendeu a formação de um plano nacional com bases científicas, de modo a reformar a educação e foi idealizada como ferramenta para o desenvolvimento do Brasil. A educação transitou como prognóstico, formulado entre as escolas de pensamento para o plano institucional, como política de Estado, que priorizou como diretriz a educação gratuita para o povo, valorizada como a portadora da mudança do ethos para o país alcançar a modernização. 
E, para além de todo o debate do período, Gustavo Capanema procurou implementar políticas de transformação da educação brasileira a partir do atendimento de demandas das diferentes escolas de pensamento da educação. Não podemos afirmar que isso tenha sido feito de forma pacífica e sob a égide do consenso, porém, entendemos que houve um esforço de acomodação de demandas que possibilitou a implementação de políticas públicas de longa duração, e, ainda influenciou a implementação da Universidade do Brasil. 


\section{Referências}

AMARAL, Azevedo. “O exército e a educação Nacional.” Nação Armada, n. 4, 1940.

AZEVEDO, Fernando. Novos caminhos e novos fins. A nova política da educação no Brasil. São Paulo, Nacional, 1931.

A cultura brasileira: introdução ao estudo da cultura no Brasil. Editora Universidade de Brasília. $4^{\circ}$ edição (revista e ampliada), 1963.

BORGES, Juliano Luis. "Raça e evolução social em "Os Sertões" de Euclides da Cunha.” Revista Espaço Acadêmico, n 58 - março de 2006.

CARONE, Edgard. A segunda república (1930-1937). 3. ed. São Paulo: Difel, 1978.

CUNHA, Euclides Rodrigues Pimenta Da. Os sertões: campanha de Canudos. 5 ed. Rio de Janeiro: Tecnoprint, 1969.

CURY, Carlos Roberto Jamil. Por um Sistema Nacional de Educação. São Paulo: Editora Moderna, 2010.

Ideologia e Educação Brasileira. São Paulo: Cortez \& Moraes, 1978.

DAROS, Maria das Dores. "Intelectuais e projetos educacionais em disputa no Brasil dos anos de 1930-1940.” Revista Roteiro, v. 39, p. 255, 2013.

; PEREIRA, Elaine Aparecida Teixeira. “A sociologia cristã e o pensamento de Alceu Amoroso Lima em um colégio católico de formação de professoras em Santa Catarina." Revista brasileira de história da educação, Maringá-PR, v. 15, n. 1 (37), p. 235-267, jan./abr. 2015

DUTRA, Eliana de Freitas; MOLLIER, Jean Yves. Política, Nação e Edição - o Lugar dos Impressos na Construção da Vida. Editora Annablume, 2006.

FAUSTO, Boris. A educação na Primeira República. In: FAUSTO, B. História Geral da Civilização Brasileira. Rio de Janeiro: Bertrand Brasil, 2006. Tomo III, v. 9.

GODOY, José Henrique Artigas. "D. Helder e Lebret: economia humana e desenvolvimentismo católico." In: $39^{\circ}$ Encontro Anual da Associação Nacional de PósGraduação em Ciências Sociais (ANPOCS), 2015, Caxambu/MG. Anais do 39 Encontro Anual da Anpocs, de 26 a 30 de outubro de 2015, em Caxambu - MG. São Paulo: Associação Nacional de Pós-Graduação em Ciências Sociais (ANPOCS), 2015. v. 1.p. 1-36.

MANNHEIM, Karl. O conceito sociológico de pensamento. In: FORACCHI, M. (org.) Mannheim. São Paulo: Ética, 1982a. (Grandes Cientistas Sociais: 25).

O problema do intelectual. In: FORACCHI, M. (org.) Mannheim. São Paulo: Ética, 1982b. (Grandes Cientistas Sociais: 25). 
MARTINS, L. "A gênese de uma intelligentsia: os intelectuais e a política no Brasil 1920 a 1940." Revista Brasileira de Ciências Sociais, São Paulo, v.2, n.4, p.65-87, 1987.

MARTINS, Wilson. História da Inteligência Brasileira. Volume VII (1933-1960). 2. ed. São Paulo: T. A. Queiroz, Editor, 1996.

NAGLE, Jorge. Educação e sociedade na Primeira República. São Paulo: EPU; Rio de Janeiro: Fundação Nacional de Material Escolar, 1974.

NASCIMENTO, Alessandra. Fernando de Azevedo: dilemas da institucionalização da sociologia no Brasil. Editora Unesp/Cultura, 2012.

SCHWARTZMAN, Simon; BOMENY, Helena Maria Bousquet; COSTA, Vanda Maria Ribeiro. Tempos de Capanema. Rio de Janeiro: Paz e Terra, 1984.

SKINNER, Quentin. "Significado y compreensión en la historia de las ideas." Revista Prismas, v. 04, p. 149-191, 2000. 